\title{
122. Simultaneous Measurement of Respiration and the Motive Force of Protoplasmic Streaming in the Myxomycete Plasmodium. III. The Effect of Oxygen Tension*)
}

\author{
By Noburô Kamiya, Shigemi Abe, and Hiromichi Nakajima \\ Department of Biology, Faculty of Science, and Laboratory for \\ Protein Research, Osaka University \\ (Comm. by Y. KuwADA, M.J.A., Oct. 13, 1958)
}

During the last two decades there have been several works dealing with the effect of low oxygen tension on the protoplasmic streaming in the plasmodium. ${ }^{1-6)}$ All of the recent works were performed on Physarum polycephalum. Ohta, ${ }^{4)}$ Kamiya, ${ }^{5)}$ and Kamiya, Nakajima, and $\mathrm{Abe}^{6)}$ measured the motive force responsible for the protoplasmic streaming under modified oxygen tensions by means of the doublechamber method. It is to be noticed that the results obtained by these authors invariably showed increase rather than decrease in the motive force under reduced oxygen tension, although, quantitatively speaking, there was some difference in the degree of response according to individual samples.

As to the respiration of Physarum plasmodium under different oxygen tensions, there is the work of Allen and Price. ${ }^{2)}$ They reported that $\mathrm{O}_{2}$-uptake is greatly influenced by low oxygen tension, but the degree of inhibition is different to a considerable extent according to the size of the plasmodium as well as to the physiological conditions of individual samples.

Thus in order to establish a definite relationship between the respiration and the production of the motive force, it is to be desired that both be measured at the same time in one and the same plasmodium so that errors caused by the differences in individual samples may be excluded.

In the present work, the simultaneous measurement of the two was conducted using gas mixtures of oxygen and nitrogen in various different ratios. Physarum polycephalum served as material. In each experiment $30 \mathrm{mg}$ of the plasmodium was used, i.e. each of the two compartments contained $15 \mathrm{mg}$ of the plasmodium, which was spread on a thin agar sheet lining the bottom of the compartment. The two compartments of the double-chamber are equipped each with two small vents with stop-cocks, which were used for replacing the gas in the compartments with another gas through perfusion. The concentrations of oxygen used were: $1 \%, 2 \%, 2.5 \%, 3 \%, 5 \%, 20 \%$ (control), $50 \%$, and

*) Supported by a Grant in Aid from the Ministry of Education. 
$100 \%$. The gas spaces of the two compartments, or $v_{L}$ and $v_{R}$ as referred to in our previous report,, were reduced both to $2.1 \mathrm{ml}$ by filling the inner spaces partially with paraffin, and the effective crosssectional areas of the capillaries attached to the compartments were both $1.38 \mathrm{~mm}^{2}$.

The present experiments were performed in three steps; first, measurement when the chamber is filled with air (20\% oxygen), which served as control; second, measurement in the gas mixture of oxygen and nitrogen in various ratios; and third, measurement in air again.

In the figure is presented an example of the experiments performed using $2.5 \%$ oxygen. It is shown that in $2.5 \%$ oxygen the amplitude of the wave representing the motive force (dynamoplasmogram) was increased to about twice as great as that obtained under the normal state $\left(20 \%\right.$ oxygen), while the oxygen uptake $\left(\mathrm{Q}_{\mathrm{o}_{2}}\right)$ was decreased to about half the normal level, or more exactly, from $10.4 \mu \mathrm{l} / \mathrm{mg} / \mathrm{hr}$ to

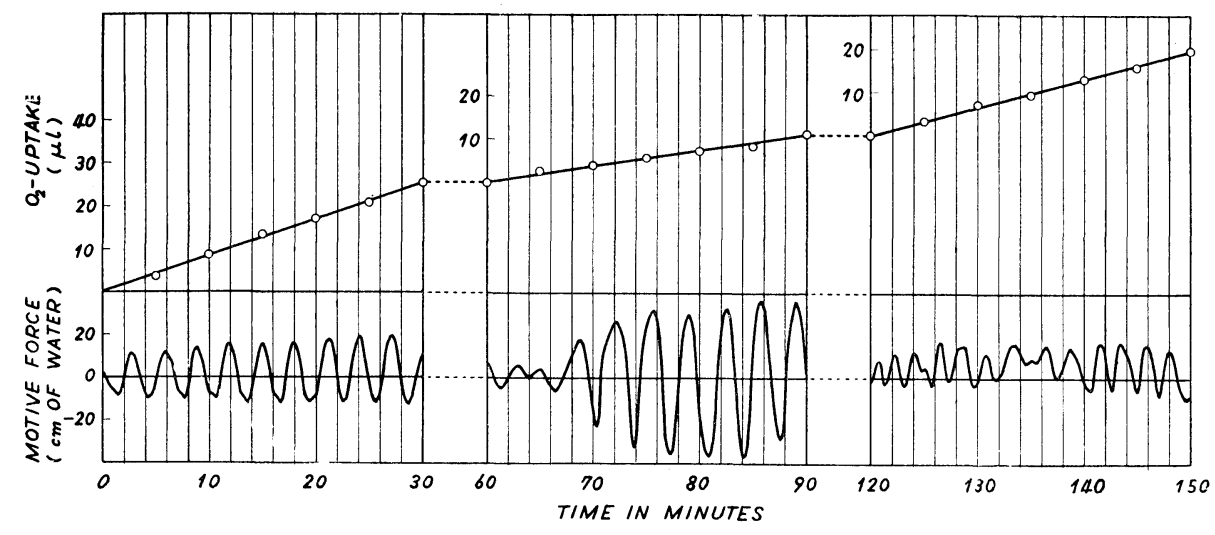

$\mathrm{O}_{2}$-uptake and motive force generation of one and the same plasmodium (Physarum polycephalum $)$ in the air $\left(20 \% \mathrm{O}_{2}\right)$ [left], 2.5\% $\mathrm{O}_{2}$ [center], and again in the air [right]. The air in the chamber was replaced by perfusion (34-47 $\mathrm{min})$ with the gas mixture $\left(2.5 \% \mathrm{O}_{2} / 97.5 \% \mathrm{~N}_{2}\right)$, which was again replaced by perfusion $(96-109$ min) with air. Temp.: $26.5^{\circ} \mathrm{C}$

$4.5 \mathrm{ll} / \mathrm{mg} / \mathrm{hr}$ on the dry weight basis. When $2.5 \%$ oxygen was replaced with air again, the respiration soon approached the normal level with the $\mathrm{Q}_{\mathrm{O}_{2}}$ of $8.0 \mu \mathrm{l} / \mathrm{mg} / \mathrm{hr}$. As for the motive force as represented by the amplitude of the wave, it decreased so much that it grew even smaller than that of the control seen on the left. Suppression of the motive force lasting for some time after the material was brought to the aerobic state from the anaerobic state has been already remarked by $\mathrm{Ohta}^{4)}$ and by ourselves. ${ }^{5) 6}$

The behaviour of the plasmodium in 1\% and $2 \%$ oxygen was basically the same in respect to the respiration and the motive force 
production. $\mathrm{O}_{2}$-uptake was reduced to the level of 30-50\% of the control, but resumed sooner or later the normal level when the material was brought back to the air. The motive force was augmented under $1-2 \%$ oxygen to $130-250 \%$ of the control in the air.

In the atmosphere containing 5\% oxygen, however, no difference was found any longer from the control both in respiration and in motive force production. To cite an example of the data of respiration in $5 \%$ oxygen, $\mathrm{Q}_{\mathrm{O}_{2}}$ in the air was first $11.0 \mu \mathrm{l} / \mathrm{mg} / \mathrm{hr}$; in the atmosphere containing $5 \%$ oxygen it was 11.7 ; when this was replaced with air (20\% oxygen), $\mathrm{Q}_{\mathrm{O}_{2}}$ remained the same, i.e. 11.7 .

We have also examined the effect of partial pressure of oxygen higher than that of the air. But neither in $50 \%$ nor in $100 \%$ oxygen, $\mathrm{O}_{2}$-uptake was modified to any discernible extent. Ohta ${ }^{4)}$ reported that the generation of the motive force is inhibited to a certain degree in pure oxygen without being accompanied by any visible changes in the structure or organization of the plasmodium. In our experiments, we could find no significant sign of inhibition or of stimulation of the motive force under higher tensions of oxygen.

Reviewing our experiments, we can say that the $\mathrm{O}_{2}$-uptake is generally depressed considerably when the partial pressure of oxygen is less than $2.5 \%$, although the sensitivity of the plasmodium to the lack of oxygen differs more or less from specimen to specimen. What has been made clear in the present experiments is that whenever respiration is inhibited under reduced oxygen tension, the motive force generated in it is always augmented and that if the $\mathrm{O}_{2}$-uptake remains constant the motive force also remains unaffected.

It might seem at first sight queer that the respiration is decreased and the motive force is increased, but this is quite natural if the energy needed for the production of the motive force is supplied by the fermentation process. Viewed in this light, the increase in the motive force is comprehensible as being due to stimulation of fermentation as a result of Pasteur effect. ${ }^{8)}$

\section{References}

1) Kitching, J. A., and Pirenne, M. H.,: J. Cellul. Comp. Physiol., 16, 131 (1940).

2) Allen, P. J., and Price, W. H.,: Amer. J. Bot., 37, 393 (1950).

3) Loewy, A. G.,: J. Cellul. Comp. Physiol., 35, 151 (1950).

4) Ohta, J.,: Cytologia, 17, 300 (1952).

5) Kamiya, N.,: Ann. Rep. Sci. Works Osaka Univ., 1, 53 (1953).

6) Kamiya, N., Nakajima, H., and Abe, S.,: Protoplasma, 48, 94 (1957).

7) Kamiya, N., Abe, S., and Nakajima, H.,: Proc. Japan Acad., 33, 206 (1957).

8) Ohta, J.,: J. Biochem., 39, 489 (1954). 
Corrigendum: In the second report of this series [Proc. Japan Acad., $33,408]$, we presented a figure showing the effect of cyanide. In this figure, the numbers in the ordinate representing the $\mathrm{O}_{2}$-uptake in $\mu \mathrm{l}$ should be multiplied by 4 ; for instance, $2 \mu \mathrm{l}$ should be $8 \mu \mathrm{l}$; $4 \mu \mathrm{l}$ should be $16 \mu \mathrm{l}$; and so on. The text needs no correction. 